\title{
As transações entre varejistas e fornecedores de frutas, legumes e verduras na cidade de São Paulo
}

\author{
Roberta de Castro Souza,*, Gabriela Scur ${ }^{\mathrm{b}}$ \\ a,*robertacsouza@usp.br, EPUSP, Brasil \\ bgabriela.sul@gmail.com, FEl, Brasil
}

\begin{abstract}
Resumo
0 objetivo deste artigo é caracterizar as estratégias usadas por três diferentes formatos de varejo (grande rede, associações de pequenos e médios supermercados e supermercados independentes) em suas compras de frutas, legumes e verduras (FLV) com foco na questão dos padrões de qualidade exigidos. A abordagem teórica utilizada é de economia dos custos de transação. Para a pesquisa empírica é utilizado o método de casos múltiplos viabilizado por meio de entrevistas presenciais com representantes dos distintos formatos de varejo na cidade de São Paulo. Os resultados indicam que há diferenças nas estratégias dos variados formatos de varejo com seus fornecedores de FLV. No caso de pequenos e médios supermercados é bastante representativo o fornecimento proveniente da Ceagesp (Companhia de Entrepostos e Armazéns Gerais do Estado de São Paulo), mesmo para o grande varejista entrevistado; cerca de 25\% do suprimento de FLV é da Ceagesp, o que caracteriza uma relação de mercado. 0 restante é fornecido pelos chamados distribuidores de origem. Por fim, os resultados do artigo têm implicações gerenciais para os produtores de FLV, indicando que há alternativas de inserção nas cadeias produtivas de FLV tendo em vista os diferentes formatos de varejo e suas estratégias distintas de relacionamento com fornecedores.
\end{abstract}

Palavras-chave

Varejo. Fornecedores. Padrões. Estratégia.

\section{Introdução}

Em termos de estudos a respeito de cadeias produtivas há vários trabalhos sobre a questão do poder nas cadeias produtivas e a importância do segmento de comercialização neste contexto. Estudos apontam que, para alguns produtos, o segmento de transformação vem perdendo poder de negociação junto aos agentes que comercializam os produtos, tais como supermercados e hipermercados (FULPONI, 2006; JAFFEE; MASAKURE, 2005; GARCIA; POOLE, 2004).

Para alimentos em geral, esse processo tem levado a uma série de investigações sobre as relações entre os agentes das cadeias produtivas e a discussão sobre o poder de supermercados e hipermercados como indutores de mudanças nas cadeias. Um elemento importante nessa discussão é a concentração do setor varejista. No final da década de 90, os dez primeiros grupos varejistas europeus já detinham 34\% das vendas totais na
Europa, enquanto as dez principais indústrias de bens de consumo detinham somente 14\% das vendas no continente (GURDJIAN et al., 2000).

Em mercados maduros, como aqueles de países europeus, os supermercados chegam a deter $80 \%$ da venda de alimentos. No entanto, em países como o Brasil, houve uma diminuição da concentração do segmento varejista associada com a expansão dos supermercados independentes (aqueles com no máximo quatro lojas com o mesmo (NPJ) - em termos de número de estabelecimentos e participação de mercado e do varejo tradicional apenas o número de estabelecimentos (FARINA; NUNES; MONTEIRO, 2005). Há indicações de que setor varejista no Brasil está sinalizando uma tendência diferente comparada com o consenso geral de alta concentração das vendas em grandes redes varejistas (REARDON; BERDEGUÉ, 2002; VORLEY, 2003). 
Em relação à literatura, há poucos trabalhos que tratam da realidade dos supermercados em países em desenvolvimento, bem como investigam o relacionamento dos diferentes formatos de varejo, em países em desenvolvimento, com produtores de FLV (REARDON; HENSON; BERDEGUÉ, 2007). De acordo com Mainville e Reardon (2007), a literatura não contempla a questão dos canais de mercado domésticos de supermercados em países em desenvolvimento e, em particular, como os padrões de qualidade e exigências em termos de produto e processo dos supermercados locais são transmitidos para os produtores locais e os afetam. Monteiro (2007) também salienta a importância da investigação dos diferentes formatos de varejo ao se discutir a questão da concentração do setor varejista no Brasil.

Diante disso, o objetivo deste artigo é caracterizar as estratégias usadas por três diferentes formatos de varejo (hipermercados, associações de pequenos e médios supermercados e supermercados independentes) em suas compras de frutas, legumes e verduras (FLV) com foco na questão dos padrões de qualidade exigidos e o impacto dessas exigências sobre a cadeia produtiva.

0 artigo está estruturado em seis seções. Depois desta introdução há a seção 2, onde é mostrada a abordagem teórica utilizada, isto é, a da economia dos custos de transação. Posteriormente, a seção 3 trata da questão dos varejistas e a importância do setor de FLV no Brasil. A seção 4 apresenta a metodologia utilizada no artigo; a 5 mostra a análise dos resultados, seguida das considerações finais.

\section{Abordagem teórica - economia dos custos de transação (ECT)}

A economia dos custos de transação (ECT) é utilizada para caracterizar o relacionamento entre varejistas e seus fornecedores de FLV. Essa abordagem é microanalítica e tem como foco o estudo da transação. Segundo Williamson (1985), os custos de transação podem ser divididos em custos de informação, de negociação e de monitoramento. A ECT pressupõe que a transação envolve riscos, e as partes, para se proteger desses riscos, criam mecanismos e estruturas de governança para reduzi-los.

Os pressupostos da ECT são racionalidade limitada e possibilidade de comportamento oportunista dos agentes envolvidos na transação. Ao se realizar uma determinada transação, os agentes não possuem todas as informações a respeito e têm racionalidade limitada para analisar todas as situações que poderiam ser desencadeadas por aquela relação contratual. Além disso, os agentes que, por exemplo, detiverem alguma informação privilegiada (informação assimétrica), a respeito da transação, podem usá-la de maneira oportunista no futuro. Sendo assim, problemas desse tipo podem elevar os custos de transação.

Dados os pressupostos de racionalidade limitada e oportunismo, torna-se necessário identificar os principais atributos das transações, para assim poder analisar os custos de transação envolvidos e a estrutura de governança ideal para cada caso, ou seja, a estrutura de governança que irá diminuir os custos de transação envolvidos.

As principais estruturas de governança são o livre mercado (ou mercado spot), formas híbridas e integração vertical. A primeira forma de comercialização tem como maior exemplo as feiras livres, nas quais as transações ocorrem sem que haja nenhum compromisso das partes em realizá-las novamente, dentro das mesmas condições. Já a estrutura híbrida pode ocorrer de diversas formas e implica em certo compromisso no fornecimento.

Como exemplos de formas de comercialização híbridas têm-se as franquias, os contratos formais de longo prazo, os contratos "não formais" de longo prazo, as parcerias, redes de cooperação, entre outros. A estrutura de governança hierárquica é representada pela integração vertical, na qual vários segmentos da cadeia produtiva têm um único proprietário (FARINA; AZEVEDO; SAES, 1997).

Dependendo da magnitude da especificidade do ativo exigido nessa transação, os agentes econômicos irão escolher a forma de comercialização ou estrutura de governança que proporcione o menor custo de transação. Quanto maior a especificidade do ativo envolvido na transação, maior a necessidade de controle, maior a tendência à adoção da integração vertical como estrutura de governança (ZYLBERSTAJN, 1995).

Segundo Williamson (1991), a especificidade de ativos pode se caracterizar por seis formas distintas. São elas: (1) especificidade locacional: está diretamente relacionada ao transporte e armazenagem de produtos específicos de uma certa transação; (2) especificidade de ativos físicos e (3) humanos: diz respeito aos ativos físicos e aos recursos humanos que foram investidos para realizar determinada transação e que não podem ser reaproveitados, sem perdas de valor, em outro tipo de transação; (4) especificidade de ativos dedicados: são os ativos investidos numa transação com um agente particular; (5) especificidade de 
marca: relacionada aos investimentos na marca de uma empresa, que compreende aspectos como reputação, confiabilidade do consumidor na marca de uma determinada empresa; e (6) especificidade temporal: quando o valor da transação depende, sobretudo, do tempo em que ela se processa (FARINA; AZEVEDO; SAES, 1997, p. 87). Extremamente relevante para produtos perecíveis, que vão perdendo seu valor ao longo do tempo e cuja transação deve ser feita rapidamente.

Já a frequência com que uma transação é realizada tem importância para a diluição dos custos dos mecanismos utilizados na realização da transação, fundamental na escolha da estrutura de governança. A maior frequência na realização de uma transação também possibilita que os agentes envolvidos tenham maior conhecimento uns dos outros e que construam uma reputação.

No caso da terceira dimensão da transação, a incerteza, o aumento desta envolve o crescimento dos custos de transação envolvidos, pois os agentes irão despender mais recursos para estabelecer mais salvaguardas contratuais e monitorar a transação ex-post (enforcement). Já as estruturas de governança que se encontram entre a estrutura de mercado e a integração vertical, as chamadas formas híbridas de governança, podem ser encontradas em formas variadas, tais como redes de firmas, contratos de longo prazo, franquias, parcerias, dentre outras (MENARD, 2002).

As estruturas híbridas de governança se desenvolvem por causa das vantagens esperadas em função da dependência mútua. Já o nível e as formas dos investimentos específicos necessários para a transação determinarão a significância dos riscos contratuais e a natureza das salvaguardas necessárias para assegurar o acordo. Na forma híbrida de governança podem ser encontradas parceria, contrato formal e contrato informal (FAULIN; AZEVEDO, 2003).

Outro elemento importante que incentiva a adoção de formas híbridas de governança é a marca. Caso para um dos agentes envolvidos na transação a manutenção da reputação da marca seja elemento importante, há um incentivo para adoção de formas híbridas. Em um extremo, esse fato levaria à integração vertical como forma de governança.

A abordagem teórica de economia dos custos de transação foi aplicada em um estudo de canais de distribuição de hortaliças na cidade de São Carlos (SP), e os resultados revelam que as relações entre varejo e fornecedores podem ser via mercado ou formas híbridas de governança.

\section{0 setor varejista no Brasil}

Segundo a Pesquisa Anual de Comércio (PAC) do Instituto Brasileiro de Geografia e Estatística (IBGE), em 2006 o comércio varejista era composto por 1,3 milhão de empresas, despendeu entre salários, retiradas e outras remunerações R\$ 39,8 bilhões, corresponde a 83,6\% do total das empresas comerciais no Brasil e possui uma taxa de margem de comercialização* de 33,3\%.

De maneira geral, nos segmentos do comércio varejista predominam as empresas de menor porte, com até 19 pessoas ocupadas. No entanto, um dos segmentos que vêm se destacando no cenário varejista é o de hipermercados e supermercados. Apesar de a participação desse segmento no comércio varejista total, em termos de número de empresas, não ultrapassar $0,8 \%$, este gerou $\mathrm{R} \$ 100$ bilhões em receita líquida de revenda, o que corresponde a $22,8 \%$ do total.

As duas principais fontes no país para classificação das lojas deste segmento do varejo são a empresa ACNielsen e a Associação Brasileira de Supermercados, Abras. A classificação dos diferentes formatos de loja, segundo a Abras, tem por base a área de vendas e o número de check-outs. Por outro lado, a ACNielsen ressalta que o varejo tradicional é aquele em que um vendedor está presente para servir os consumidores, e os formatos podem ser classificados em função da propriedade, isto é, uma rede de supermercados é formada por no mínimo cinco lojas que possuem a mesma bandeira (CNPJ). Já o formato varejo independente é aquele que possui até quatro lojas com o mesmo CNPJ.

De maneira geral, o varejo de produtos frescos na cidade de São Paulo pode ser classificado em três tipos: as grandes e modernas redes de supermercado e hipermercados com grande escala de vendas de FLV; o segundo grupo, constituído por pequenas e médias redes de supermercado que se caracterizam como firmas independentes e pequenas redes; e o terceiro tipo, formado por lojas especializadas com forte foco na venda de perecíveis, ou exclusivamente na venda de produtos frescos (MAINVILLE; REARDON; FARINA, 2008).

Até os anos 80, o varejo brasileiro se caracterizava por concorrência regional, lojas especializadas atuando apenas localmente, redes regionais e poucas cadeias de lojas no cenário nacional (ALMEIDA, 2006). Já na década de 90, houve a grande transformação do setor varejista de alimentos com o controle da inflação, a melhor distribuição de renda e a estabilidade econômica, que estimularam

* Taxa de margem de comercialização: corresponde à divisão da margem de comercialização pelo custo da mercadoria revendida. 
a expansão das empresas nacionais. Somado a isso, houve a abertura comercial e a saturação dos mercados em países desenvolvidos, que incentivou o fluxo de investimento em mercados emergentes, como o brasileiro. Como fruto do intenso fluxo de investimentos, em 2007, dentre as cinco principais redes de supermercado no Brasil, apenas uma é totalmente brasileira, a Cia. Zaffari, do Rio Grande do Sul (para maiores detalhes ver Tabela 1).

A literatura sobre supermercados ressalta a questão da tendência à concentração desse setor e seus possíveis impactos sobre a cadeia, e mais precisamente sobre fornecedores. Os estudos sobre o assunto apontam que os resultados de inúmeras cadeias produtivas são largamente determinados pelos supermercados. Exigências relativas à qualidade, confiabilidade, custo, variedade, valoradicionado, inovação, segurança alimentar e comércio justo são demandas do segmento varejista (BROWN, 2005).

Dentre as exigências também destacam-se os sistemas de qualidade como o Boas Práticas Agrícolas e de Fabricação e a APPCC - Análise dos Perigos e Pontos Críticos de Controle, que tem como função detectar nos processos produtivos os principais pontos de contaminação. Há também os certificados criados por grupos de supermercados, como é o caso do EurepGap, e aqueles criados por redes de supermercado individualmente, como o Nature's Choice (da rede supermercadista Tesco, a maior da Inglaterra) (HINGLEY; HOLLINGSWORTH, 2003; HUMPHREY, 2005; VORLEY, 2003; SOUZA, 2005).

De maneira geral, pode-se observar que a expansão das vendas do grande varejo é mais rápida e expressiva no caso de alimentos processados e embalados. Já no caso dos alimentos frescos, como as frutas e vegetais, a expansão é mais lenta. Em 1989, a participação dos supermercados do Reino Unido nas vendas de FLV era de 33\%; já em 2003, essa porcentagem subiu para 80\% (BROWN, 2005).

Tabela 1. Os cinco principais varejistas no Brasil - 2007.

\begin{tabular}{ccc}
\hline Supermercados & País de origem & $\begin{array}{c}\text { Market share* } \\
(\%)\end{array}$ \\
\hline $\begin{array}{c}\text { Carrefour } \\
\begin{array}{c}\text { Companhia Brasileira } \\
\text { de Distribuição } \\
\text { Wal-Mart }\end{array}\end{array}$ & $\begin{array}{c}\text { França } \\
\text { (grupo Casino) }\end{array}$ & 21 \\
G. Barbosa & $\begin{array}{c}\text { Estados Unidos } \\
\text { Adquirida pela rede } \\
\text { chilena Cencosud }\end{array}$ & 16 \\
Cia. Zaffari & Brasil & 2 \\
\hline
\end{tabular}

${ }^{*} 0$ market share foi calculado com base no faturamento total declarado somente pelas 500 maiores empresas. Fonte: elaborado pelas autoras com base nos dados da Abras (2008).
Em se tratando do Brasil, na cidade de São Paulo, as grandes redes de varejo detêm 75\% da venda de alimentos processados contra $25 \%$ da venda de alimentos frescos. No caso da França, enquanto a participação do varejo na venda de alimentos é de 70\% a 80\%, nas vendas de frutas e vegetais frescos a participação é de 50\%. Essa participação é ainda mais baixa em países asiáticos, como Malásia, Indonésia e Tailândia, em que essa porcentagem varia de $15 \%$ a $20 \%$ (REARDON et al., 2003). Sendo assim, uma pergunta importante é se seria possivel generalizar as estratégias utilizadas pelos varejistas relativas ao fornecimento. Este artigo parte do pressuposto que os diferentes formatos de varejo possuem estratégias distintas.

Segundo Humphrey (2007), há evidências de que grandes lojas, em países em desenvolvimento, não têm a preferência do consumidor nas compras de produtos frescos, e a chave para a expansão dos grandes varejistas nas vendas de produtos frescos seria atingir mercados consumidores de baixa renda com lojas menores.

Conforme Farina, Nunes e Monteiro (2005), no Brasil houve uma desconcentração do varejo de alimentos associada à expansão de supermercados independentes $^{\dagger}$ (em termos de número de estabelecimentos e participação de mercado) e do varejo tradicional (somente em número de estabelecimentos) $)^{\ddagger}$. Outro fato a destacar é que, no ano de 2007, os supermercados de pequeno e médio porte registraram maior lucratividade se comparado com as grandes redes. A grande dimensão territorial do Brasil ajuda o estabelecimento de redes regionais que atendem as preferências de mercados distantes dos grandes centros comerciais. Esse fato indica que o setor varejista de alimentos no Brasil vem sinalizando uma tendência diferente do consenso geral, representada pela alta concentração das vendas pelas grandes redes de supermercado (REARDON; BERDEGUÉ, 2002; UK COMPETITION COMMISSION, 2000, 2008; VORLEY, 2003).

Além disso, em entrevistas presenciais realizadas com atacadistas de FLV na Ceagesp, em junho de 2007, pôde-se constatar o aumento da importância de formatos de varejo tais como pequenos e médios supermercados no comércio de legumes e verduras, bem como as chamadas lojas especializadas na venda de produtos frescos. Segundo alguns entrevistados, os fornecedores de legumes e verduras, que antes vendiam para grandes redes de varejo, atualmente

\footnotetext{
+ Segundo ACNielsen (2007) o formato varejo independente é classificado em função da propriedade. Aquela rede constituída de até 4 lojas com o mesmo CNPJ pode ser classificada como varejo independente.

‡ Segundo ACNielsen, varejo tradicional é aquele onde um vendedor está
} presente para servir os consumidores. 
preferem pequenos e médios supermercados e lojas especializadas na venda de perecíveis devido ao alto número de exigências estabelecido pelas grandes redes, que afetava diretamente suas margens de lucro.

De fato, a literatura sobre varejo ressalta a importância da coordenação vertical exercida por grandes redes varejistas junto a seus fornecedores para garantir alguns padrões de qualidade e sua estratégia de diferenciação de produto (HUMPHREY, 2007). No entanto, no Brasil, os dados da Ceagesp mostram que o volume comercializado de FLV tem permanecido constante do ano de 2004 a 2007 (Tabela 3). As compras feitas na Ceagesp podem ser consideradas como uma estrutura de governança de mercado.

Segundo informações da Associação Brasileira de Supermercados - Abras (ASSOCIAÇÃ̃O..., 2007), a participação nas vendas das cinco maiores redes de supermercado não ultrapassa $40 \%$ desde o ano de 2000 (Tabela 2). Segundo Rojo (2007), os pequenos e médios varejistas vêm investindo em qualificação, tecnologia e conhecimento de mercado, além do atendimento personalizado, que é apontado como o item de maior importância para o consumidor na escolha da loja. Além disso, os hábitos de consumo indicam compras mais frequentes em lojas de vizinhança, o que mostra tendência de diminuição do número de lojas.

Por último, vale ressaltar a importância da formação de redes e associações de negócios, constituídas por pequenos e médios varejistas interessados, dentre outras coisas, em aumentar seu poder de barganha nas negociações com fornecedores.

Tabela 2. Participação do varejo nas vendas de alimentos e de frutas e vegetais frescos em alguns países.

\begin{tabular}{ccc}
\hline Paises & $\begin{array}{c}\text { Porcentagem do } \\
\text { varejo nas vendas de } \\
\text { alimentos (\%) }\end{array}$ & $\begin{array}{c}\text { Porcentagem do varejo } \\
\text { nas vendas de frutas e } \\
\text { vegetais frescos }(\%)\end{array}$ \\
\hline França & $70-80$ & 50 \\
Indonésia & 33 & $15-20$ \\
Malásia & 33 & $15-20$ \\
Tailândia & 33 & $15-20$ \\
Coreia & 63 & 30 \\
Taiwan & 63 & 30 \\
Filipinas & 63 & 30 \\
\hline
\end{tabular}

Fonte: baseado em Reardon, et al. (apud SOUZA; AMATO, 2006).

Tabela 3. Volume comercializado em toneladas de FLV pela Ceagesp - de 2004 a 2007.

\begin{tabular}{crrrr}
\hline FLV/anos & \multicolumn{1}{c}{2004} & \multicolumn{1}{c}{2005} & \multicolumn{1}{c}{2006} & \multicolumn{1}{c}{2007} \\
\hline Frutas & 1.453 .545 & 1.526 .016 & 1.548 .740 & 1.590 .707 \\
Legumes & 696.724 & 730.020 & 745.407 & 756.748 \\
Verduras & 222.959 & 226.892 & 229.199 & 213.631 \\
\hline
\end{tabular}

Fonte: Ceagesp (COMPANHIA..., 2008).

\section{Método}

0 método escolhido para análise empírica foi o estudo de casos múltiplos. Segundo Yin (2001), o método estudo de caso é usado para solucionar questões do tipo como ou por que sobre um conjunto contemporâneo de acontecimentos, do qual o pesquisador tem pouco ou nenhum controle (YIN, 2001, p. 28). 0 estudo de casos múltiplos é uma variação do estudo de caso que permite a compreensão de diferentes aspectos de um determinado fenômeno (EISENHARDT, 1989; MALHOTRA, 2001; VOSS; TSIKRITSIS; FROHLICH, 2002). Segundo Lazzarini (1997), o estudo multicaso permite utilizar mais de uma unidade de análise e focar a questão da interpretação dos fatos, não sua mensuração.

As críticas ao método escolhido estão relacionadas à possibilidade de haver problemas na replicação da pesquisa científica e à generalização dos resultados. No entanto, o objetivo do método é proporcionar generalizações teóricas, e isso pode ser beneficiado com a realização de mais de um caso (EASTERBY-SMITH; THORPE; LOWE, 2002; VOSS; TSIKRITSIS; FROHLICH, 2002). Segundo Eisenhardt (1989) e Malhotra (2001), é fundamental que os estudos de caso sejam realizados de maneira estruturada, de modo a ter um processo replicável. Segundo Miguel (2007), é fundamental na utilização do método estudo de caso a elaboração de um protocolo de pesquisa onde devem estar definidos: (a) o contexto da pesquisa (área e local, procedimentos e fontes de informação), (b) a parte a ser investigada (unidade de análise), e, por fim, (c) os meios de controle da pesquisa (formulação das chamadas variáveis de controle).

Foram realizadas entrevistas presenciais com representantes de diferentes formatos de varejo na cidade de São Paulo. As três empresas foram selecionadas a partir do ranking publicado pela Abras e pela Latin Panel. A primeira empresa entrevistada foi uma grande rede de supermercados, chamada varejo A, que está entre as quatro maiores redes no Brasil. 0 segundo caso é o Supermercado Pastorinho, que pode ser caracterizado como supermercado independente. Segundo a ACNielsen, as redes de varejo são aquelas com cinco ou mais lojas com o mesmo nome, e supermercado independente é aquele que possui, no máximo, quatro lojas com o mesmo nome. 0 Supermercado Pastorinho é o $15 .^{\circ}$ maior varejista do estado de São Paulo. 0 terceiro caso é uma associação de pequenos e médios supermercados, a Arcos, que é a maior desse tipo do estado. 
Quadro 1. Protocolo de pesquisa.

\begin{tabular}{|c|c|c|}
\hline Contexto da pesquisa & Parte a ser estudada & Meios de controle da pesquisa \\
\hline $\begin{array}{l}\text { Três varejistas da cidade de São Paulo: um grande } \\
\text { varejista, um varejista independente e uma associação } \\
\text { de supermercados. } \\
\text { Fontes de informação: consulta a documentos da Abras, } \\
\text { entrevistas presenciais com o presidente da Abras e com } \\
\text { os agentes responsáveis pela compra de FLV de cada um } \\
\text { dos supermercados citados. }\end{array}$ & $\begin{array}{l}\text { Unidade de análise: } \\
\text { transações do varejo } \\
\text { com fornecedores de } \\
\text { FLV. }\end{array}$ & $\begin{array}{l}\text { Variáveis de controle: dimensões da transação } \\
\text { a) especificidade de ativos; b) frequência; e c) incerteza. } \\
\text { a) especificidade de ativos: relacionada ao grau de } \\
\text { exigência dos varejistas em relação a seus fornecedores } \\
\text { de FLV - solicitação de padrões públicos e privados. } \\
\text { b) frequência: refere-se a quão recorrente são realizadas } \\
\text { as transações entre os agentes. }\end{array}$ \\
\hline
\end{tabular}

Os três casos foram analisados a partir da definição das chamadas variáveis de controle (Quadro 1). As variáveis de controle foram estabelecidas de acordo com as três dimensões da transação definidas pela economia dos custos de transação. A especificidade de ativos foi definida em função das exigências dos supermercados em relação aos seus fornecedores de FLV. Foram especificados os padrões ditos públicos e os padrões privados. A dimensão frequência refere-se à quão recorrente são realizadas transações entre os agentes. No caso de FLV, por causa da perecibilidade dos produtos, a frequência tende a ser maior.

\section{Análise dos resultados}

\subsection{Primeiro caso: Varejo $A$}

0 primeiro caso deste artigo é o varejo $A$, que está entre as quatro maiores redes de supermercado do Brasil. 0 varejo A centralizou a distribuição de seus produtos a partir de 2001 e, atualmente, a empresa tem 14 centros de distribuição, sendo sete deles especificamente para FLV (baseada em pesquisa de campo, 2008; Panorama SuperHiper, 2007). As vendas de produtos perecíveis (carnes, laticínios e FLV) representou 30,2\% do faturamento da empresa em 2007.

Para a pesquisa de campo foi realizada entrevista presencial com o gerente responsável pela seleção dos fornecedores de FLV e pelo monitoramento das atividades de produção e preparação desses produtos. Atualmente, o varejo tem 800 fornecedores de FLV, e cerca de apenas 25\% do fornecimento de FLV vem do entreposto da Ceagesp. A estrutura de governança predominante é a consignação que é caracterizada pelo relacionamento direto da rede varejista com o produtor e também com o chamado distribuidor de origem. 0 distribuidor de origem pode ou não ser produtor, mas suas principais características são o relacionamento direto com o varejista e possuir parcerias com produtores para obter a quantidade de produtos demandados pelo comprador. 0 varejista conhece a propriedade dos parceiros, mas não mantém relações diretas com este produtor parceiro do distribuidor de origem.

A pesquisa de campo mostrou que, no passado, o varejista comprava FLV, principalmente, do distribuidor de destino, que é aquele atacadista que em geral atua próximo à Ceagesp e tem uma certa infraestrutura para preparar FLV para o ponto de venda. No entanto, devido ao aumento das exigências relacionadas à segurança do alimento, passou-se a negociar mais com o distribuidor de origem que tem maior conhecimento a respeito da produção de FLV propriamente dita e maior conhecimento quanto às condições em que estes alimentos são produzidos. 0 distribuidor de origem é o responsável junto ao supermercado pela qualidade dos produtos fornecidos pelos parceiros e, por vezes, financia as atividades do parceiro por meio de adiantamento para o pagamento dos insumos necessários à produção.

0 varejo A credencia seus fornecedores de FLV a partir de dois critérios: o técnico e o comercial. 0 critério técnico é baseado nas normas da Agência Nacional de Vigilância Sanitária - Anvisa, por meio das quais foi elaborado um check list composto por 130 itens e que podem ser resumidos nos padrões: 5S, Boas Práticas Agrícolas, Boas Práticas de Manufatura (no galpão de embalamento), Procedimento Operacional Padrão e Análise dos Perigos e Pontos Críticos de Controle (APPCC). Já o critério comercial é baseado na regularidade de entrega, segurança alimentar e quantidade.

Para se tornar um fornecedor da rede, a propriedade agrícola é submetida a uma vistoria por uma equipe de funcionários do varejo A. Nessa vistoria a equipe atribui uma nota ao fornecedor baseado no check list composto de 130 itens citado anteriormente. Quanto maior o número de itens atendidos, maior a nota. Caso o fornecedor consiga boas notas e desenvolva tanto o seu padrão técnico quanto o comercial leva por volta de três anos para que este seja alçado a fornecedor marca própria. Este fornecedor pode comercializar seus produtos com a marca do supermercado, marcas 1 e 2 neste caso. Vale lembrar que a marca 1 tem cerca de 
80 fornecedores, e a marca 2, 11 fornecedores. Essas marcas são vendidas principalmente nas lojas menores do grupo voltadas para um público diferenciado. Segundo a pesquisa de campo, a grande vantagem de ser um fornecedor marca própria é a venda de grandes volumes ao varejo A.

Vale lembrar que apesar das vistorias realizadas pela rede nas áreas de produção, o supermercado apenas detecta os problemas na produção, mas não fornece nenhum tipo de treinamento ao fornecedor. Os produtores devem buscar informações de como produzir dentro dos parâmetros a partir de outras fontes. Neste caso, um grande papel é desempenhado pelo chamado distribuidor de origem que mantém relações diretas com o varejo A e é produtor (algumas vezes) e estabelece parcerias com outros produtores transferindo informações sobre o quanto e como produzir e, algumas vezes, financiando as atividades dos parceiros.

Tendo em vista as estratégias dos varejistas ressaltadas por Humphrey (2007), a estrutura de governança estabelecida pelo varejo A nas suas relações com fornecedores pode ser caracterizada como coordenação vertical que é baseada em centros de distribuição para FLV de maneira geral e em fornecedores preferenciais no caso das marcas 1 e 2 .

\subsection{Segundo caso: supermercado independente - Pastorinho}

0 Pastorinho é uma rede originada no interior do estado de São Paulo. Atualmente, a rede comercializa seus produtos com apenas uma bandeira, e possui quatro unidades na cidade de São Paulo. Esse fato o caracteriza como um supermercado independente segundo a classificação da ACNielsen. As estratégias utilizadas pela rede na compra de FLV são diferenciadas. As frutas são compradas no entreposto da Ceagesp, dos permissionários, e estas são transportadas para as lojas pelo próprio supermercado.

Os legumes são comprados de distribuidores, que possuem packing-houses localizadas próximas à Ceagesp. Esses distribuidores são empresas que possuem um galpão para preparação da fruta perto da Ceagesp. Nesse galpão, os legumes que vêm de produtores e da própria Ceagesp são lavados, selecionados e retirados das caixas de madeira e postos em caixas de papelão. Com esses distribuidores, o Pastorinho já se relaciona há 20 anos e eles mesmos fazem as entregas nas lojas. No caso das verduras, estas são compradas diretamente de dois produtores ou de uma cooperativa de produtores, a CAISP (Cooperativa Agropecuária de lbiúna). Tanto as verduras quanto os legumes são fornecidos diariamente.

Segundo a pesquisa de campo, os produtores de frutas e legumes são mais especializados do que os produtores de verduras. Sendo assim, no caso da verdura é possível conseguir o volume e variedade necessários de apenas dois produtores. Outro importante fornecedor de verduras é a CAISP, com quem a rede mantém um relacionamento de oito anos e que fornece para as outras três lojas localizadas na cidade de São Paulo. Uma das vantagens apresentadas por se negociar com a CAISP é o fato de obter maior variedade e volume com apenas uma negociação.

Essa rede, ao contrário do varejo $A$, não tem centro de distribuição e este é o argumento para que não compre em grandes volumes. As compras de FLV são feitas diariamente, o que facilita 0 planejamento da demanda. A única forma de fiscalizar a qualidade do produto é a vistoria no ponto de venda. Quando há algum problema de qualidade ou alta perecibilidade do produto, as perdas são descontadas da nota de pagamento que será emitida para o fornecedor posteriormente. Ou seja, as perdas são de responsabilidade dos fornecedores, o que evidencia um relacionamento de consignação. Além disso, quanto aos preços, estes são definidos em função da cotação diária da Ceagesp.

\subsection{Terceiro caso: associações de pequenos e médios varejistas}

As associações são responsáveis por 13\% das vendas totais do setor, e o principal objetivo de seus membros é aumentar o poder de barganha ao negociar com fornecedores. 0 processo de consolidação das associações passa por diferentes fases. A primeira delas é quando as empresas se unem para comprar em conjunto e obter melhores preços. A segunda fase é quando as empresas compram em conjunto, mas já estão mais orientadas para sortimento e variedade. Em um terceiro estágio, as associações passam a realizar programas de treinamento para os funcionários das empresas que compõem a rede. No quarto estágio, a associação parte para a formação de uma empresa limitada e cria um centro de distribuição para gerir estoques e fazer as negociações (ROJO, 2007). A associação escolhida para pesquisa de campo, Arcos, é a terceira maior do estado de São Paulo (ASSOCIAÇÃO..., 2007). A Arcos está na primeira fase no processo de consolidação das associações. 


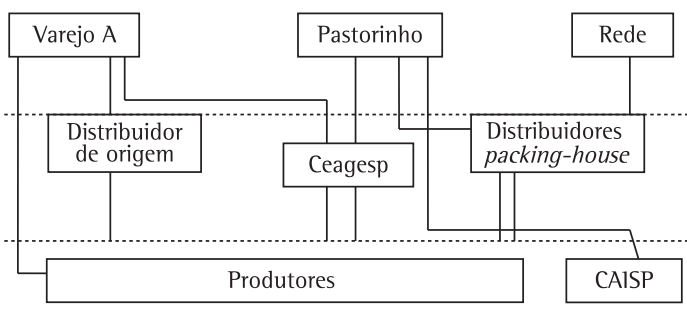

Figura 1. Agentes e transações entre varejo e fornecedores de FLV. Fonte: elaborado pelas autoras.

Segundo a pesquisa de campo, a associação compra FLV dos atacadistas localizados próximos à Ceagesp, o que caracteriza uma relação de mercado. As lojas dos membros da associação são abastecidas de FLV três dias da semana e os atacadistas são responsáveis pelo transporte até as lojas, já que a organização não possui centro de distribuição. Em relação à qualidade, FLVs são inspecionados apenas na chegada às lojas e a associação não exige nenhum tipo de certificação de seus fornecedores.

Um resumo dos agentes participantes e das relações entre varejo e fornecedores de FLV por ser visto na Figura 1.

\section{Considerações finais}

0 objetivo deste artigo foi caracterizar as estratégias usadas por três diferentes formatos de varejo (grande rede, supermercados independentes e associações de pequenos e médios supermercados) em suas compras de frutas, legumes e verduras (FLV) com foco na questão dos padrões de qualidade exigidos. A literatura sobre supermercados ressalta que a principal estratégia dos varejistas é a diferenciação do produto, o que implica em uma relação mais próxima com seus fornecedores de FLV. Sendo assim, uma importante questão que surge é se seria possível generalizar as estratégias dos varejistas com esses fornecedores. Este artigo parte do pressuposto que não é possível generalizar, pois os diferentes formatos de varejo adotam estratégias distintas com seus fornecedores de FLV, o que, de fato, foi confirmado com a pesquisa empírica.

No caso do varejo A, 25\% de FLV são fornecidos pela Ceagesp, o que caracteriza uma relação de mercado. 0 restante é proveniente dos chamados distribuidores de origem, que podem ser produtores ou não, mas têm como principal característica ter parcerias com outros produtores. Quando os distribuidores de origem não podem fornecer a quantidade demandada pelos supermercados, eles compram dos parceiros. Algumas vezes, os distribuidores de origem chegam a conceder financiamento para seus parceiros produzirem FLV para garantir o volume e a quantidade exigida pelo supermercado.

De acordo com a literatura sobre supermercados, os distribuidores de origem atuam como fornecedores preferenciais e, no caso do varejo A, eles estão registrados no banco de dados da rede. Grandes redes como o varejo $A$, que possuem marcas próprias, acabam por manter relações mais próximas com o fornecedor no sentido de garantir um fornecimento de hortaliças dentro dos padrões de qualidade do supermercado.

Por meio de coleta de dados realizada na Ceagesp, pode-se observar que o volume comercializado de FLV de 2004 a 2007 permaneceu constante. Este fato mostra que apesar do aumento do relacionamento diretamente com produtores, evidenciado com a entrevista com o varejo A (grande rede), os supermercados independentes e associações podem representar grande participação nas vendas de FLV ao consumidor final tendo em vista o volume comercializado pela Ceagesp.

No caso do Supermercado Pastorinho, este compra a maior parte das frutas e legumes da Ceagesp no sistema de consignação. A outra parte é fornecida pelos atacadistas localizados próximos à Ceagesp, que lavam e selecionam o produto para o supermercado. Além disso, este atacadista transfere os produtos das caixas de madeira para caixas plásticas para que possam ser transportados para as lojas do Pastorinho. Esse tipo de varejo não desenvolve uma coordenação vertical como ocorre com o varejo A. A transação do Supermercado Pastorinho com os atacadistas próximos à Ceagesp é de alta frequência e de longo prazo (quase 20 anos). Apesar de ser uma transação de consignação e sem contratos formais, é um relacionamento antigo em que está envolvida a confiança entre os agentes. Sendo assim, é classificada como uma relação de consignação, baseada em confiança. A consignação é interpretada como uma forma híbrida de governança, assim como já visto em Souza (2005) quando caracterizou as relações entre produtores de manga e uva e compradores europeus.

É possivel afirmar que as estratégias do segmento varejista variam em função do formato desse varejo. Também é possível verificar que essas variações têm feito com que os atacadistas adquiram novas funções na cadeia produtiva, como é o caso do atacadista localizado próximo à Ceagesp e o caso do distribuidor de origem ressaltado no caso do varejo $A$. 
Em termos de implicações gerenciais, os resultados indicam que as diferentes estratégias dos varejistas podem nortear novas estratégias de inserção dos produtores nessas cadeias produtivas, principalmente para pequenos e médios produtores, bem como políticas públicas neste sentido. Em termos de implicações teóricas, a literatura sobre supermercados enfatiza as estratégias de diferenciação e de fornecedores preferenciais de grandes redes de supermercados com seus fornecedores de FLV, e os resultados da pesquisa indicam que não é possível generalizar essas estratégias para todos os formatos de varejo.

\section{Referências}

ALMEIDA, P. A evolução e estratégias do setor varejista no brasil. Gestão Universitária, n. 84, 2006.

ASSOCIAÇÃO BRASILEIRA DE SUPERMERCADOS - ABRAS. SUPERHIPER Panorama 2007. ABRAS, 2007.

BROWN, 0. Supermarket buying power, global commodity chains and smallholder farmers in the developing world. Human Development Report, 2005.

COMPANHIA DE ENTREPOSTOS E ARMAZÉNS GERAIS DO ESTADO DE SÃO PAULO - CEAGESP. Disponível em: <www.ceagesp.gov.br>. Acesso em: 20 mar. 2008.

EASTERBY-SMITH, M.; THORPE, R.; LOWE, A. Management research an introduction. London: Sage, 2002.

EISENHARDT, K. M. Building theories from case study research. Academy of Management Review, v. 14, n. 4, p. 532-550, 1989.

FARINA, M. M. Q. F.; AZEVEDO, P. F.; SAES, S. Competitividade: mercado, estado e organizações. São Paulo: Singular, 1997.

FARINA, E. M. M. Q.; NUNES, R.; MONTEIRO, G. F. Supermarkets and their impacts on the agrifood system of Brazil: the competition among retailers. Agribusiness, v. 21, n. 2, p. 133-147, 2005. http:// dx.doi.org/10.1002/agr.20039

FAULIN, E. J.; AZEVEDO, P. F. Distribuição de hortaliças na agricultura familiar: uma análise das transações. Informações Econômicas, v. 33, n. 11, 2003.

FULPONI, L. Private voluntary standards in the food system: the perspective of major food retailers in OECD countries. Food Policy, v. 31, n. 1, p. 1-13, 2006. http:// dx.doi.org/10.1016/j.foodpol.2005.06.006

GARCIA, M.; POOLE, N. The impact of private safety and quality standards for fresh produce exports from Mediterranean countries. Food Industry Management Unit, Department of Agricultural Sciences, Imperial College, University of London. Disponivel em: <www. imperial.ac.uk/agriculturalsciences/cfcr/>. Acesso em: 13 jul. 2004.

GURDJIAN, P. et al. Bagging Europe's groceries. The McKinsey Quarterly, 2000. Disponível em: <www. mckinseyquarterly.com/countrie/baeu00.asp>. Acesso em: out. 2008.
HINGLEY, M.; HOLLINGSWORTH, A. Competitiveness and power relationships: where now for the UK food supply chain? In: ANNUAL INDUSTRIAL MARKETING PURCHASING (IMP), 19., 2003, Lugano, Switzerland. Anais... Lugano, 2003. Disponível em: <www.impgroup. org>. Acesso em: 15 maio 2005.

HUMPHREY, J. Shaping value chains for development: global value chains in agribusiness. Trade Programme, Federal Ministry for Economic Cooperation and Development, Eschborn, 2005.

HUMPHREY, J. The supermarket revolution in developing countries: tidal wave or tough competitive struggle? Journal of Economic Geography, v. 7, p. 433-450, 2007. http://dx.doi.org/10.1093/jeg/lbm008

JAFFEE, S.; MASAKURE, O. Strategic use of private standards to enhance international competitiveness: vegetable exports from Kenya and elsewhere. Food Policy, v. 30, p. 316-333, 2005.

LAZZARINI, S. G. Estudos de caso: aplicações e limites do método. In: Farina, E. M. M. Q. Estudos de caso in Agribusiness. São Paulo: Pioneira, 1997.

MAINVILLE, D. Y.; REARDON, T. Supermarkets marketchannel participation and technology of horticultural producers in Brazil. Revista de Economia e Sociologia Rural, v. 45, n. 3, p. 705-727, 2007. http://dx.doi. org/10.1590/S0103-20032007000300007

MAINVILLE, D. Y.; REARDON, T.; FARINA, E. M. M. Q. Scale, scope, and specialization effects on retailers' procurement strategies: evidence from the fresh produce markets of São Paulo. Revista de Economia e Sociologia Rural, v. 46, n. 1, p. 207-227, 2008.

MALHOTRA, N. Pesquisa de marketing: uma orientação aplicada. 3. ed. Porto Alegre: Bookman, 2001.

MENARD, C. The economics of hybrid organizations. Presidential adress. International Society for New Institutional Economics. MIT, USA. September, 2002.

MIGUEL, P. A. C. Estudo de caso na engenharia de produção: estruturação e recomendações para sua condução. Produção, v. 17, n. 1, p. 216-229, 2007. http://dx.doi. org/10.1590/S0103-65132007000100015

MONTEIRO, G. F. A. Estrutura de mercado e concorrência no varejo de alimentos: o mercado de consumo integrado. 2007. 111 f. Dissertação (Mestrado em Economia)Universidade de São Paulo, São Paulo, 2007.

REARDON, T. et al. The rise of supermarkets in Africa, Asia, and Latin America. American Journal of Agricultural Economics, v. 85, n. 5, p. 1140-1146, 2003. http:// dx.doi.org/10.1111/j.0092-5853.2003.00520.x

REARDON, T.; BERDEGUÉ, J. The rapid rise of supermarkets in Latin America: challenges and opportunities for development. Development Policy Review, v. 20, n. 4, p. 371-388, 2002. http://dx.doi.org/10.1111/1467-7679.00178

REARDON, T.; HENSON, S.; BERDEGUÉ, J. Proactive fasttracking diffusion of supermarkets in developing countries: implications for market, institutions and trade. Journal of Economic Geography, 2007, p.1-33.

R0J0, F. Brasil infinitas oportunidades. SuperHiper Panorama 2007. Associação Brasileira de Supermercados - ABRAS, 2007. 
SOUZA, R. C. Uma investigação sobre o segmento produtor de manga e uva in natura em sua inserção na cadeia de valor global. 2005. 197 f. Tese (Doutorado em Engenharia de Produção)-Universidade de São Paulo, São Paulo, 2005.

SOUZA, R. C.; AMATO, J. Exportações brasileiras de frutas certificadas: oportunidades de negócios para o empresário rural. In: ZUIN, L. F. S.; QUEIROZ, T. R. Agronegócio: gestão e inovação. São Paulo: Saraiva, 2006.

UK COMPETITION COMMISSION. Supermarkets: a report on the supply of groceries from multiple stores in the United Kingdom. London, UK: Competition Commission, 2000. Disponível em: <www.competitioncommission.org.uk/rep-pub/reports/2000>. Acesso em: 10 fev. 2005.

UK COMPETITION COMMISSION. Final report 2008: grocery market investigation. 2008. Disponível em: <http:// www.competition-commission.org.uk/inquiries/ ref2006/grocery/groceries_inquiry_news.htm>. Acesso em: 20 out. 2008.

VORLEY, B. Corporate Concentration from farm to consumer. UK Food Group, 2003. Disponivel em: <www.ukfg. org>. Acesso em: 10 fev. 2005.
VOSS, C.; TSIKRITSIS, N.; FROHLICH, M. Case research: case research in operations management. International Journal of Operations \& Production Management, v. 22, n. 2, p. 195-219, 2002. http://dx.doi.org/10.1108/01443570210414329

WILLIAMSON, O. E. The economic institutions of capitalism - firms, markets, relational contracting. New York: Free Press, 1985.

YIN, R. K. Estudo de caso: planejamento e métodos. Porto Alegre: Bookman, 2001.

ZYLBERSZTAJN, D. Estruturas de governança e coordenação do agribusiness: uma aplicação da nova economia das instituições. Tese (Livre Docência)-Universidade de São Paulo, São Paulo, 1995.

\section{Agradecimentos}

Este trabalho é resultado de projeto de pesquisa financiado pela Fundação de Amparo à Pesquisa do Estado de São Paulo - FAPESP.

\title{
The transactions between supermarkets and fresh fruit and vegetables (FFV) suppliers in the São Paulo, Brazil
}

\begin{abstract}
The objective of this article is to characterize the strategies used by three different retail formats (large retail chains, associations of small and mid-size supermarkets and independent supermarkets) in their purchase of fruit and vegetables, focused on the issue of quality standard requirements of the different retail formats in the city of São Paulo. The conceptual approach uses the economic theory of transaction costs. The empirical part of the project uses the method of multiple case studies, which was made viable by face-to-face interviews with representatives from the different kinds of retail businesses in Sao Paulo. The outcome indicates that there are differences in the procurement strategies at different retail formats. For small and medium supermarkets, the supply of fresh fruit and vegetables by the Sao Paulo Wholesale Trading Terminal of fresh food (called Ceagesp) is still representative. Even in the case of large retailers, about 25\% of FFV is provided by "Ceagesp", which characterizes an arm's length relationship as a procurement strategy. The other part is supplied by distributors of origin, which can be considered first-tier suppliers.
\end{abstract} Keywords

Supermarket. Suppliers. Standards. Strategy. 